\title{
Benign Peritoneal and Retroperitoneal Neoplasm
}

National Cancer Institute

\section{Source}

National Cancer Institute. Benign Peritoneal and Retroperitoneal Neoplasm. NCI

Thesaurus. Code C156713.

A non-metastasizing neoplasm that affects the peritoneum and/or retroperitoneum. 